\title{
Asocolderma: desafíos actuales
}

Afectuoso saludo,

Terminando nuestro primer semestre a cargo de la presidencia de AsoColDerma, quisiera hacer un repaso sobre la situación de nuestra especialidad y de los retos que se aproximan en un futuro cercano.

Al inicio de este año, nos encontramos con que debemos volvernos retenedores de IVA cuando se realicen "tratamientos de belleza - cirugías estéticas", según el parágrafo 3 del artículo 4 , en concordancia con el artículo 10 de la Ley 1943 de 2018, conocida como Ley de financiamiento. Después de una reunión con funcionarios de la DIAN y del Ministerio de Salud, quedaron todavía algunos vacíos con respecto a la definición de dichos procedimientos, aunque dejan a la autonomía y al criterio profesional del médico la posibilidad de establecer la pertinencia y el concepto de estos, fijando como marco de referencia para distinguir entre cirugías estéticas y reparadoras o funcionales las definiciones dadas en el artículo 8, numerales
7 y 8 de la Resolución No. 5857 de 2018, expedida por el Ministerio de Salud y Protección Social, y la sentencia T-003 de 2019 de la Corte Constitucional (1). Como recomendación queda que debemos asesorarnos con un profesional contador con experiencia en el tema, ya que cada caso es especial y requiere un manejo individual.

De acuerdo con la Ley 1712 de 2014, conocida como Ley de transparencia, y la Resolución 2881 de 2018 del Ministerio de Salud y la Protección Social, se estableció como obligación de la industria farmacéutica informar a este ministerio acerca de las transferencias de valor que hagan a los médicos, que van desde las muestras médicas hasta los apoyos en educación continuada, dentro de unos rangos de valores previamente estipulados. Se realizó una reunión con un abogado experto en el tema, la cual fue grabada y montada en la página para que todos la pudiéramos ver. La industria nos está solicitando la firma del consentimiento con ese fin; queda a la voluntad de cada uno de nosotros hacerlo o no, teniendo en cuenta que si no se firma con algún laboratorio simplemente no podemos esperar ninguna transferencia de valor por parte de dicha empresa. Queda en el aire la inquietud acerca de la finalidad de dicha información.

Continuamente estamos recibiendo información acerca de diplomados y cursos orientados al entrenamiento en temas de estética, principalmente, a grupos de personas, que van desde técnicos, bacteriólogos, odontólogos, hasta médicos generales, entre otros. Con el apoyo del grupo de abogados contratados por la Asociación, se está realizando seguimiento $y$, en los casos que lo ameriten, apertura de procesos ante las entidades correspondientes. Solicitamos encarecidamente a los asociados que eviten apoyar dichas actividades, en la medida en que tal conducta podría constituir una violación a los principios, obligaciones y deberes que tenemos como asociados (contenidos en los estatutos y la legislación médica) e igualmente una vulneración de los intereses éticos, profesionales,

${ }^{1}$ Corte Constitucional, sentencia T-003 de 2019, magistrado ponente Cristina Pardo Schlesinger: “...la cirugía estética con fines de embellecimiento es aquella que no tiene una patología de base y busca exclusivamente embellecer o rejuvenecer tejidos sanos o normales de las personas. La cirugía estética reconstructiva (incluida en el POS) tiende a recuperar la forma o la función perdida como consecuencia de un trauma o una enfermedad". 
académicos, científicos y gremiales que nos identifican como organización.

Hace pocos días emitimos un comunicado para recordar las competencias del dermatólogo (donde hacemos énfasis en temas generales, aunque, específicamente, en el manejo del cáncer cutáneo), el cual va a ser difundido a las EPS e instituciones de medicina prepagada, pues nos hemos visto desplazados en el manejo de algunas patologías.

De igual manera, les queremos recordar que la práctica de la llamada "consulta asistida" es un procedimiento que, en concepto de la Personería de Bogotá, "infringe las normas del Sistema General de Seguridad Social en Salud y podría ir en contra de la salud de los pacientes". Así mismo, les recomendamos a los colegas asociados que se abstengan de contratar sus servicios en esos términos, como quiera que estamos en la obligación de formular quejas ante la Secretaría Distrital de Salud para que se investiguen a las entidades prestadoras de servicios médicos involucradas y presentar quejas disciplinarias contra los profesionales que auspicien 0 participen en este tipo de prácticas, que desconocen los principios éticos que rigen nuestra profesión, previstos en la Ley 23 de 1981, y los principios que regulan el sistema de seguridad social en salud, contenidos principalmente en las leyes 1438 de 2011 y 1751 de 2015.

Estamos trabajando con el fin de mejorar cada vez más la práctica de nuestra especialidad. Por esta razón, quisiera recordarles a todos ustedes la importancia de apoyar a
Uniderma, que es el sindicato que puede ayudarnos a resolver situaciones de tipo laboral y contractual, que en algún momento nos tocarán afrontar.

Por último, a todos, especialmente a los jefes de escuela y grupo de residentes, les recuerdo la importancia del apoyo a nuestra revista, tanto en los artículos que serán publicados como en la referenciación en los trabajos de investigación. Es la única forma como podremos ascender en la calificación de Colciencias.

Un saludo,

\section{Óscar Mora \\ PREsidenTE DE AsOCol- DERMA}

